\section{Original article}

\title{
HIV infection among homosexual/bisexual males attending genitourinary clinics in Scotland
}

D Goldberg, G Scott, M Weir, S Cameron, J Peutherer, A McMillan, G Leadbetter, A Scoular, G Codere, G Allardice

Background: Since 1991, unlinked anonymous HIV testing of homosexual/bisexual males attending genitourinary clinics in Edinburgh and Glasgow has been conducted and resulting prevalence data have been published annually. More detailed information which provides an understanding of what proportion of HIV infected men attending genitourinary clinics in central Scotland (i) remain undetected, (ii) acquire sexually transmitted infections following HIV diagnosis, and (iii) possibly become HIV infected either abroad or following sex with someone from abroad, is reported by the authors.

Methods: Unlinked anonymous HIV testing of syphilis serology specimens from homosexual/ bisexual males attending genitourinary clinics during 1991-5.

Results: Of 3468 specimens tested, 165 (4.8\%) were HIV positive. Thirty five per cent (57) of all HIV positive specimens were from men whose infection remained undetected following clinic attendance. Of the 80 attenders who knew themselves to be HIV positive before their clinic visit, $13 \mathrm{had}$ clinical and/or laboratory evidence of a sexually transmitted infection. Men who had a sexual risk associated with America or who were American, had a 2.4-fold greater risk of being HIV infected than those with United Kingdom only connections.

Conclusion: Increased efforts should be made to ensure that HIV infected men are diagnosed early after infection and do not engage in high risk sexual behaviour, and that all homosexual men are educated about the particular risks of acquiring HIV infection abroad. More effective interventions to prevent indigenous HIV transmissions need to be developed.

(Sex Transm Inf 1998;74:185-188)

Keywords: HIV; homosexual men; unlinked anonymous HIV testing; Scotland

Environmental Health,

Ruchill Hospital,

Glasgow

D Goldberg

G Codere

G Allardice

\section{Department of}

Genitourinary

Medicine, Royal

Infirmary, Edinburgh

G Scott

A McMillan

Department of

Genitourinary

Medicine, Royal Free

Hospital, London

$M$ Weir

Regional Virus

Laboratory, Ruchill

Hospital, Glasgow

$S$ Cameron

Regional Clinic, Virus Laboratory, City

Hospital, Edinburgh

J Peutherer

G Leadbetter

Department of Genitourinary

Medicine, Royal

Infirmary, Glasgow

A Scoular

Correspondence to:

Dr David Goldberg, Scottish

Centre for Infection and

Environmental Health,

Ruchill Hospital, Glasgow

G20 9NB.

Accepted for publication

12 February 1998

(Royal Infirmary and Southern General Hospitals) and Edinburgh (Royal Infirmary); these clinics serve $98 \%$ and $100 \%$ of their respective city populations though unknown numbers of people with problems relating to sexually transmitted infections present to their general practitioner or do not seek medical attention. Homosexual/bisexual male attenders of genitourinary clinics are therefore not representative of the homosexual population at large, nor of homosexual men who are at risk of sexually transmitted infection; while this group is self selected, the method of unlinked anonymous HIV testing ensures that participation bias is negligible.

All attenders presenting with a new risk for sexually transmitted disease are tested routinely for syphilis serology. Any leftover serum is anonymised and tested for HIV-1 antibodies if attenders have presented for the first time in a calendar quarter and if they have not objected; literature explaining that unlinked anonymous HIV testing is being conducted is readily available in each of the clinic settings. The anonymous testing procedure ensures that it is impossible to inform someone of their HIV test result. However, limited non-identifying epidemiological data are recorded on a proforma which bears two identical coded numbers. One is printed on an adhesive label which is applied to the patient's blood specimen so that the test result can be matched thereafter with the corresponding epidemiological details. These include sexual orientation, sex,

\section{Patients and methods}

Since late 1990, unlinked anonymous HIV testing has been carried out on specimens from attenders of genitourinary clinics in Glasgow 
Table 1 Awareness of HIV infection by year

\begin{tabular}{lccllr}
\hline \multicolumn{7}{c}{ Number HIV antibody positive } \\
\cline { 2 - 6 } Year & No of tests & $\begin{array}{l}\text { Awareness before } \\
\text { consultation } \\
\text { No (\%) }\end{array}$ & $\begin{array}{l}\text { Diagnosed during } \\
\text { consultation } \\
\text { No (\%) }\end{array}$ & $\begin{array}{l}\text { Undetected at end of } \\
\text { consultation } \\
\text { No (\%) }\end{array}$ & $\begin{array}{l}\text { Total } \\
\text { No (\%) }\end{array}$ \\
\hline 1991 & 791 & $46(5.8)$ & $24(52)$ & $6(13)$ & $16(35)$ \\
1992 & 703 & $41(5.8)$ & $22(54)$ & $6(15)$ & $13(32)$ \\
1993 & 739 & $32(4.3)$ & $12(38)$ & $7(22)$ & $13(41)$ \\
1994 & 689 & $26(3.8)$ & $14(54)$ & $5(19)$ & $7(27)$ \\
1995 & 546 & $20(3.7)$ & $8(40)$ & $4(20)$ & $8(40)$ \\
Total & 3468 & $165(4.8)$ & $80(48)$ & $28(17)$ & $57(35)$ \\
\hline
\end{tabular}

diagnosis relating to the clinic attendance (for example, gonorrhoea, chlamydia), year of specimen, and limited geographical characteristics which apply to lifetime HIV risk; information is collected on location(s) of risk, nationality of sexual contact(s), and nationality of patient by United Kingdom, Europe, Africa, Asia, Americas, and Oceania categories. Data are also collected on whether the patient was aware of being HIV infected before the clinic episode and, if not, whether a diagnosis of HIV was made during the episode.

Questions concerning sexual orientation, geographical characteristics, and HIV status were asked by the attending physician as part of the routine case history taking. While false or non-declaration of behavioural information is possible, the authors consider the data to be generally reliable. All those included had been prepared to reveal their sexual orientation as homosexual or bisexual and thus it seems unlikely that misinformation on other less sensitive topics would have been given. Failure of the patient to recall geographical exposure data and of the doctor to transcribe information accurately is likely in some instances. However, it should be recognised that the unlinked anonymous HIV testing process should never interfere with the amount or types of data which are collected routinely in the course of the clinical consultation or with the manner in which the information is normally obtained.

Serum was tested using an HIV-1,2 enzyme immunoassay (Wellcozyme HIV 1 and 2 Murex Diagnostics) in Edinburgh and a modified HIV particle agglutination test (Fujirebio) ${ }^{3}$ in Glasgow; in Edinburgh, reactives were confirmed by a second ELISA (Clone Systems Detect HIV 1 and 2) and by western blot (ANCOS HIV 1 and 2) while in Glasgow reactives were confirmed by western blot (Cambridge Biotech, Ortho). Comprehensive details about the process of anonymising specimens, testing them for HIV, and ascribing limited risk factor information to test results have been described previously. ${ }^{4}$

The analysis is confined to non-injecting homosexual/bisexual males, their knowledge of their HIV status, and their geographical risk characteristics which are classified into three groups in hierarchical order-(i) America, (ii) other, and (iii) United Kingdom. Thus individuals declaring any nationality or location connections with America were grouped as "America," those with any European, African, Asian, or Oceanian connections were categorised as "other", and those with United Kingdom associations only were grouped as "United Kingdom".

\section{Results}

During 1991-5, 3468 specimens from homosexual/bisexual males who attended Glasgow and Edinburgh genitourinary clinics were tested, of which 165 (4.8\%) were HIV positive; $21(0.6 \%)$ refused to be tested. A decrease in prevalence was observed from $5.8 \%$ in the early 1990 s to $3.7 \%$ in 1995 (table 1). The decline was particularly pronounced in Edinburgh where prevalence decreased from $6.4 \%$ to $3.1 \%$ over the 5 year period. Of the 165 HIV positive specimens, 80 (48\%) were from men who knew themselves to be infected before the clinic visit, $28(17 \%)$ were from those diagnosed positive as a result of the consultation, and 57 (35\%) originated from males whose infection status remained undetected following clinic attendance (table 1). These proportions did not vary significantly over time or between cities. The 80 attenders who knew themselves to be HIV positive before the clinic visit underwent syphilis serology testing because they had engaged in sexual activity which had placed them at risk of acquiring a sexually transmitted infection; four of these were diagnosed as having a first occurrence of genital warts, four had gonorrhoea, three had a first occurrence of herpes, and two had non-specific urethritis.

While approximately one quarter of the 3468 specimens tested during 1991-5 were from men who had a geographical connection outside the United Kingdom, a much higher proportion $(40 \%)$ of the positives originated from this group (table 2). Those who had experienced risk in America or with men of American nationality, or who were American nationals had a 2.4-fold greater risk of being HIV infected than those with United Kingdom only connections; of the 26 positives with associations with America only four were American nationals. Men with "other" connections, mostly European, were less likely to be infected than the America population but were still at significantly greater risk than the United Kingdom only group. The population attributable risks for HIV infection conveyed by (i) an American, and (ii) a non-United Kingdom association were $17.5 \%$ and $26.1 \%$ respectively.

The geographical gradation of risk generally applies throughout the 5 year period though

Table 2 HIV infection hazard by geographical exposure

\begin{tabular}{|c|c|c|c|c|c|c|c|c|c|c|c|c|c|c|c|c|c|c|c|}
\hline \multirow{2}{*}{$\begin{array}{l}\text { Geographical } \\
\text { connection }\end{array}$} & \multicolumn{3}{|c|}{1991} & \multicolumn{3}{|c|}{1992} & \multicolumn{3}{|c|}{1993} & \multicolumn{3}{|l|}{1994} & \multicolumn{3}{|c|}{1995} & \multicolumn{4}{|c|}{$1991-5$} \\
\hline & No & + & $\%$ & No & + & $\%$ & No & + & $\%$ & No & + & $\%$ & No & + & $\%$ & No & + & $\%$ & $R R(C I)$ \\
\hline America & 51 & 7 & 13.7 & 54 & 7 & 13.0 & 59 & 4 & 6.8 & 58 & 4 & 6.9 & 53 & 4 & 7.5 & 275 & 26 & 9.4 & $2.41(1.6,3.65)$ \\
\hline Other & 135 & 9 & 6.7 & 131 & 8 & 6.1 & 151 & 10 & 6.6 & 125 & 7 & 5.6 & 123 & 6 & 4.9 & 665 & 40 & 6.0 & $1.54(1.1,2.2)$ \\
\hline UK & 605 & 30 & 4.9 & 518 & 26 & 5.0 & 529 & 18 & 3.4 & 506 & 15 & 3.0 & 370 & 10 & 2.7 & 2528 & 99 & 3.9 & 1 \\
\hline
\end{tabular}


there was a decrease in prevalence between 1991 and 1995 for each geographical group; $45 \%$ reductions were seen in the United Kingdom and America populations and a $27 \%$ decrease was observed in the "other" category. Thus, the overall decline in prevalence from $5.8 \%$ in 1991 to $3.7 \%$ in 1995 is a product of decreases in prevalence among all homosexual/ bisexual males attending genitourinary clinics in Scotland regardless of where and with whom they had sexual relations.

\section{Discussion}

The decrease in HIV prevalence among homosexual/bisexual men attending genitourinary clinics in central Scotland during 1991-5 is encouraging and is of the same magnitude as that seen among attenders of clinics in England and Wales outside the south east over the same period. ${ }^{5}$ In London and the south east, the only part of the United Kingdom where prevalence appears to differ considerably, a decrease from $22 \%$ in 1990 to $10 \%$ in 1995 was seen. ${ }^{5}$ However, in this region, the transfer of diagnosed HIV seropositive men from clinics involved in the survey to special HIV clinics is thought to have accounted for much of the apparent decline in prevalence; this is not the case in central Scotland where the decline in prevalence probably reflected a decrease in incidence.

Nevertheless, transmissions among men who have sex with men are still occurring. During 1991-4, 22 cases in Glasgow and Edinburgh were diagnosed among men who had had a negative HIV test within the previous 24 months. ${ }^{6}$ Also it is apparent from this study that some men who knew themselves to be HIV infected were still practising unprotected sexual intercourse and some of these were contracting sexually transmitted infections. In England similar findings among males known to be HIV infected have been reported recently as has a strong association between the acquisitions of an acute sexually transmitted infection and HIV seroconversion. ${ }^{78}$ In central Scotland there are a number of organisations which have helped the great majority of men diagnosed with HIV to cope with their condition and to practise safe sex..$^{9-11}$ While much has been achieved, unprotected anal intercourse is not uncommon ${ }^{12}$; accordingly, interventions designed to modify behaviour need to be maintained and further developed.

Just over one third of infections among homosexual/bisexual males in Glasgow and Edinburgh remained undetected at the end of the clinic episode though it is possible that the occasional infected male chose not to declare his status. When compared with data on homosexual/bisexual males from England and Wales for $1994-5$, this proportion is very similar. ${ }^{5}$ However, it is much less than that for infected pregnant women in London $(84 \%)^{5}$ and much greater than that for injecting drug users throughout the United Kingdom $(10-15 \%) .^{513}$ It is estimated that approximately 200 infected homosexual/bisexual males remain undetected in Scotland. ${ }^{13}$ Furthermore, many of those who are diagnosed are being detected at a late stage of their disease; nearly half of those identified in 1994 had a first CD 4 count of less than 200 cells per $\mathrm{mm}^{3}$ in that year. ${ }^{14}$ In England and Wales it is estimated that between 500 and 1000 homosexual/bisexual males are infected annually. ${ }^{15}$ Many men have taken the reasonable decision to adopt safer sex practices but have not had an HIV test since the benefits were perceived to be minimal and the disadvantages considerable. However, given the evidence to support the early use of combination antiretroviral therapy, more proactive approaches to HIV testing have become desirable. Therapy which is tailored to reduce circulating levels of virus to almost undetectable levels may improve survival considerably. ${ }^{16}$ It may also have a public health benefit. If reducing the viral load in pregnant women lessens the chances of vertical transmission, the same is likely to apply to infection acquired through the sexual route. ${ }^{17}$ Thus, administering therapy to as many viraemic men as possible should, in theory, minimise the size of the infectious population.

Additionally, the measure which probably has the greatest impact in preventing the sexual transmission of HIV is the education of known HIV infected men and their partners about the importance of practising safe sex. Accordingly, greater effort should be expended in encouraging homosexual/bisexual males at risk to undergo HIV testing. If these efforts proved successful, the numbers of undetected infections as monitored by the unlinked anonymous testing programme would decrease to extremely low levels.

While the majority of infected cases had no connections with abroad, men who had sex with men, either of American nationality and/or in America, were at considerably greater risk of being HIV infected than those who had United Kingdom associations only. Because of the limited amount of information that can be collected in an unlinked anonymous survey lest an individual might be identified indirectly, America includes north, central, and south. However, for virtually all the attenders with American connections, genitourinary clinic staff have confirmed that America is generally synonymous with the United States. In the United States, unlinked anonymous surveys of genitourinary clinic attenders have been conducted since 1987. In all, 120 clinics throughout the United States participate in the programme and during 1991-2 the median seroprevalence among homosexual/bisexual males was $27.3 \%{ }^{18}$ While this was $5.7 \%$ less than the prevalence recorded during 1989-90 it is still extremely high and is in keeping with the greater risk conveyed to United Kingdom nationals who have homosexual contact with men from the United States.

In conclusion, the findings of this study on HIV infection among homosexual/bisexual males in Scotland indicate clearly that there are still a number of major challenges for those involved in preventive work. Increased efforts should be made (i) to ensure that HIV infected individuals are detected as soon after acquiring 
their infection as possible, (ii) to prevent people known to be infected from engaging in unprotected sexual intercourse, (iii) to design appropriate sexual health promotion campaigns for homosexual/bisexual men who travel abroad, and (iv) to develop more effective interventions to prevent indigenous HIV transmission which still accounts for the majority of infections in Scotland.

The authors would like to thank the following individuals for their very important contribution to this study: JD Dickson and ther very ids Scott (Department of Medical Microbiology, University Medical School, Edinburgh); S Sommerville (Department of burgh); E McEwan, L McWhirter, M Miller, M Knox, J Roberts, I Tai (retired), and S Wyper (Department of Genitourinary Medicine, Royal Infirmary, Glasgow); J Winning (Department of Bacteriology, Southern General Hospital, Glasgow); E Carragher, S Donald, J Emslie (retired), L Linden, W Smyth, and J Tolland (Scottish Centre for Infection and Environmenta Health); E Campbell, G Clements, E Follett (retired), R McHugh, L McDonald, and K Wilson (Regional Virus Laboratory, Ruchill Hospital, Glasgow). We are especially grateful to the Medical Research Council (Committee on the Epidemiological Study of AIDS) for funding this surveillance in its first three developmental years, and to the Scottish Office Department of Health for continued funding. Thanks also to Dr Grafor continued funding. Thanks also to Dr Graham Hart, assistant

Contributors: Dr Goldberg, as consultant epidemiologist at the Scottish Centre for Infection and Environmental Health, has coordinated the survey since its inception in 1991 . He also wrote the first draft of the paper and is the principal author. All othe authors made considerable contributions to the writing of the paper. Drs Scott, McMillan, Weir, and Scoular managed the surveys in the genitourinary clinic setting while Dr Cameron and Mrs Leadbetter managed the laboratory component of th survey. Drs Scott, Cameron, Peutherer, and Weir were al grantholders of the surveys when they were funded by the Medical Research Council. Mr Codere and Mrs Allardice managed and analysed the data at the Scottish Centre for Infection and Environmental Health.

1 Robertson JR, Bucknall ABV, Welsby PD, et al. Epidemic of AIDS related virus (HTLV III/LAV) infection amon intravenous drug users. BMF 1986;292:527-29.

2 HIV Infection and AIDS. Quarterly Report to 31 December 1996. ANSWER (AIDS News Supplement to the Weekly Report) 1997:AM-31 No 13.

3 Barbara JAJ, Salker R, Challis P, et al. Gelatin particle agglutination assay for HIV antibodies: a rapid, economical modification with increased sensitivity. Med Lab Sci 1989;135-40.
4 PHLS AIDS Centre, PHLS Virus Reference Laboratory, PHLS Statistics Unit, Academic Department of Genitourinary Medicine University College and Middlesex School of Medicine, and Collaborators. Unlinked anonymous monitoring of HIV prevalence in England and Wales: 1990-92. Commun Dis Rep 1993;3:R1-11.

5 Unlinked Anonymous HIV Prevalence Monitoring Programme England and Wales. Report from the Unlinked Aramme England and Stering Group. (Chairman: Dr Jeremy Metters, Dept of Health). Data to the end of 1995.

6 Goldberg DJ. New HIV infections among men who have sex Goldberg DJ. New HIV infections among men who have sex
with men, Scotland 1989-1994. ANSWER (AIDS News Supplement to the Weekly Report) 1995:AM-8 No 95/08.

7 Catchpole MA, Mercey DE, Nicoll A, et al. Continuing transmission of sexually transmitted diseases among patients infected with HIV-1 attending genitourinary medicine clinics in England and Wales. BMF 1996;312 531-42.

8 Williams DI, Stephenson JM, Hart GJ, et al. A case control study of HIV seroconversion in gay men, 1988-1993: what are the current risk factors? Genitourin Med 1996;72:1936 are

9 AIDS (Control) Act 1995-96. Lothian Health Board

10 AIDS (Control) Act 1995-96. Greater Glasgow Health Board.

11 Hart G, Flowers P. A survey of gay men's sexual behaviour in Glasgow. MRC Medical Sociology Unit, University of Glasgow. Report to the Greater Glasgow Health Board 1996 .

12 Scoular A, Kay E, Bell J, et al. Specific health services for gay men - are they needed? Poster presentation MSSVD spring meeting, 1995.

13 AIDS and severe HIV-related disease in Scotlandpredictions to the end of 1999. A report by a working group convened by the Chief Medical Officer for Scotland. ANSWER (AIDS News Supplement to the Weekly Report) 1995;AM-18-WR 95/52.

14 HIV and AIDS Surveillance in Scotland. Review of the Epidemic to December 1994. ANSWER (AIDS News Suppledemic to December 1994. ANSWER (AIDS News Supple-

15 Report of an Expert Group (Chairman: Professor NE Day) convened by the Director of the Public Health Laboratory Service on behalf of the Chief Medical Officers. The incidence and prevalence of AIDS and prevalence of other severe HIV disease in England and Wales for 1995 to 1999 : projections using data to the end of 1994. Commun Dis Rep 1996;6:1

16 O'Brien WA, Hartigan PM, Martin D, et al. Changes in plasma HIV-1 RNA and CD4 lymphocyte counts and the risk of progression to AIDS. N Engl f Med 1996;334:426-

17 Dickover RE, Garratty EM, Herman SA, et al. Identification of levels of maternal HIV-1 RNA associated with risk of perinatal transmission. Effect of maternal zidovudine treatment on viral load. $\mathcal{F} A M A$ 1996;275:599-605.

18 Centers for Disease Control and Prevention. National HIV Serosurveillance Summary: Results through 1992. Vol 3. Atlanta, GA: US Department of Health and Human Services, 1994. 